Max-Planck-Institut für demografische Forschung

Max Planck Institute for Demographic Research

Konrad-Zuse-Strasse $1 \cdot$ D-18057 Rostock · GERMANY

Tel +49 (0) 3812081 - 0; Fax +49 (0) 3812081 - 202;

http://www.demogr.mpg.de

MPIDR WORKING PAPER WP 2009-002

JANUARY 2009

\title{
The structure of recent first-union formation in Romania
}

\author{
Jan M. Hoem (hoem@demogr.mpg.de) \\ Dora Kostova (kostova@demogr.mpg.de) \\ Aiva Jasilioniene (jasilioniene@demogr.mpg.de) \\ Cornelia Muresan
}

(C) Copyright is held by the authors.

Working papers of the Max Planck Institute for Demographic Research receive only limited review. Views or opinions expressed in working papers are attributable to the authors and do not necessarily reflect those of the Institute. 
Final (submittable) DRAFT 08/1 2009

\title{
The structure of recent first-union formation in Romania
}

\author{
by Jan M. Hoem, Dora Kostova, Aiva Jasilioniene, and Cornelia Mureşan
}

\begin{abstract}
By European standards, consensual first unions have been rare in Romania, and they remain so even though their incidence has increased by a factor of almost five since the early 1960s. Rates of conversion of consensual unions into marriages have been cut in half over the same four decades or so, and marriage rates have declined by a similar factor since the fall of state socialism, which is more dramatic because this period is so much shorter. There have been strong ethnic differentials in union-entry rates in the country.
\end{abstract}

\section{Introduction}

There is a general impression that there is very little non-marital cohabitation in Romania (e.g. Mureşan et al., 2008). This does not really square easily with other findings by Mureşan (2007a, Table 5.5), who has estimated that one-fifth of all Romanian women would have entered a consensual union by age 40 according to the data for 1980-89 and that as many as over one-third would do so according to the data for 1996-2005. ${ }^{1}$ In fact, cohabitation may not be as rare in the country as is often supposed. In order to provide better insight into the issue of first-union formation, we use this paper to give an account of the size and structure of the incidence of marital and non-marital first-union formation over the period 1960-2005, much in the spirit of Hoem et al. (2007), where a brief extract of some of our results has appeared in a comparative context. We concentrate on the incidence (or entry "risk") because it is more sensitive to change over time and to differentials between population groups than other representations of union formation. We show that over the years since 1960 there has been a steady growth in the incidence of cohabitation. This increase is quite surprising, since the rigidity of the Romanian political system before 1989 must have suppressed the individualization of family forms suggested by the narrative of the Second Demographic Transition (Lesthaeghe and van de Kaa. 1986, Sobotka 2008) and generally prevented the change in values implied by the growth in non-marital union formation.

\section{Data and method}

We are fortunate in having early access to the data from the first wave of the Romanian Gender and Generations Survey (GGS), conducted in 2005. We use singledecrement intensity-regression to bring out the impacts of the risk factors included in this survey. We study entry into marital and non-marital unions separately and describe each of our two intensities by a piecewise-constant proportional-hazard model with age attained as process time and some fixed and time-varying covariates.

In this analysis, fixed covariates include some indicators of the respondent's socialization, namely whether at age 15 she lived with both her parents and whether

\footnotetext{
${ }^{1}$ Each estimate is produced by a competing-risk period life-table computation of first-union formation with entry into marriage as the competing risk, based on data from the national Gender and Generations Survey.
} 
she lived in an urban or rural setting. ${ }^{2}$ Another fixed covariate is the respondent's selfreported ethnicity (Romanian, Hungarian, Roma, or "other"). As reported, Romanians contribute some 90 per cent of the exposure time observed in our data, the Hungarians give some 8 per cent, and the Roma constitute a little less than 1 per cent. The specification of our other fixed covariates appears in Table 1 later in this paper.

To account for the impact of a pregnancy (which a priori we expect to boost the entry intensities), we include a time-varying covariate which we call parity-andpregnancy status. A woman is counted as childless and non-pregnant until nine months before her first birth, as childless and pregnant throughout the pregnancy, and as a mother after the arrival of her first child. (Note that we have no direct observation of pregnancies in our data, so we can only impute her pregnancy status when we know the time of her birth. Since we are dealing with the time until a woman first enters a union, there is little observed exposure after her entry into motherhood.)

Another time-varying covariate in our analysis is the respondent's educational attainment. For this covariate the first wave of the GGS (our data) contains only her educational attainment recorded at the time of the interview and the month in which she reached that attainment according to her own report. From this information we impute her educational progress using a method suggested by Hoem and Kreyenfeld (2006).

We finally pick up the change in effect over time by including a third timevarying covariate called period. We have divided the years between 1960 and 2005 into five-year periods (1960-64, 1965-69, ..., 2000-2005). For each such period we take the entry risks to be constant, but they may (and apriori probably will) vary from one five-year period to the next. For a comparison between the time trends in the intensities of our two competing risks we apply a technique described most completely by Hoem and Kostova (2008), a procedure where the mode of union formation appears formally as a covariate additional to the real risk factors. Following the recommendation of Hoem et al. (2007, Appendix) we disregard differential impacts of our risk factors in this part of our study and use them only as control variables intended to hedge against compositional effects.

\section{Trends and levels in entry risks since 1960}

The trends in entry risks appear in Figure 1, in which we have plotted maximum-likelihood estimates of the period-specific entry risks relative to the marriage intensity in 1960-64. ${ }^{3}$ In the language of classical demographic

\footnotetext{
${ }^{2}$ We have also included the number of siblings in our analysis, since studies sometimes show (Michael and Tuma 1985, Santow and Bracher 1994, Manting 1996, Kulik 2005, Koytcheva 2006, and others) that individuals with (more) siblings are more likely to form unions than individuals who grew up as an only child. The impact of the number of siblings has been so small in our study, however, that we do not even report their relative risks in Table 1 below.

${ }^{3}$ Using the symbolism suggested by Hoem et al. (2007) we include the two entry intensities jointly in the analysis by specifying the model $A+B+C D$, where factor $A$ stands for Age, $B$ for the combination of Background factors, $C$ for Calendar period, and $D$ for Decrement, i.e., for entry into marital vs. non-marital first unions. Note that we use $C$ and $D$ in interaction, and that this is the only interaction included.
} 
methodology, the trends have been standardized (using indirect standardization) with respect to the control variables listed in Table 1 below.

\section{$<$ - Figure 1 in about here ->}

It is immediately apparent in Figure 1 that the incidence of entry into cohabitation is much lower than that of marriage formation. We also see that there was a strong and sudden drop in the latter after the early 1990s; the marriage intensity was cut in half over the decade after the fall of state socialism. In the incidence of cohabitation there was a steady growth over the 40 -odd years of our period of observation. In fact we see an increase by a factor of between four and five between the early 1960s and the early years of the present century. The low level of the incidence of cohabitation is visible similarly in the age profiles given in Figure 2, which is based on single-decrement models for our two competing risks.

\section{$<$ - Figure 2 in about here ->}

\section{The structure of single-decrement first-union entry risks}

Figure 2 displays the baseline hazards in models where we have estimated entries into marital and non-marital first unions separately. The effects of our other covariates appear in the form of the two first columns of relative risks in Table 1 (plus the interaction in its Footnote d). The baseline level on each covariate is indicated by a relative risk of 1 (without decimals). Note that risk levels cannot be compared across the two modes of union entry.

As we see from the coefficients for the parity-and-pregnancy status, the arrival of a pregnancy will boost the rate of entry into either kind of union, as expected. There are also great differences in union-type-specific entry rates among the various ethnic groups. While Hungarians and "other" non-Romanian women have particularly low rates of entry into consensual unions, the Roma have particularly high rates. The latter can most likely be explained at least partly by the different perception among the Roma of what in fact is a marriage as acknowledged by their own community. (See, e.g., Koytcheva 2006, Section 4.5.2). ${ }^{4}$ This is probably also behind the low rate of conversion of consensual union into marriages among the Roma respondents that we will meet below.

\footnotetext{
${ }^{4}$ The questionnaire invited a union to be regarded as a marriage only if it was registered as such by the authorities. Otherwise it was supposed to be recorded as a consensual union.
} 
Table 1. Relative risks for control variables in single-decrement models

Conversion of cohabitation to

Mode of union entry: marriage $^{\mathrm{b}}$

Parity-and-pregnancy status

Cohabitation $^{\mathrm{a}, \mathrm{c}}$ Marriage $^{\mathrm{a}}$

$\begin{array}{lccc}\text { Childless* } & 1 & 1 & 1 \\ \text { Pregnant** } & 7.93 & 8.20 & 1.60 \\ \text { Mother } & 0.75 & 0.71 & 1.09\end{array}$

Lived with parents at age 15

Yes

(Romanians ${ }^{\mathrm{d}}$ )

No

1.73

1

1

0.77

If lived with

Ethnicity parents at age $15^{\mathrm{d}}$

$\begin{array}{lccc}\text { Romanian } & 1 & 1 & 1 \\ \text { Hungarian } & 0.57 & 1.05 & 0.53 \\ \text { Roma } & 1.80 & 0.75 & 0.28 \\ \text { Other } & 0.33 & 1.26 & 0.53\end{array}$

Location at age 15

$\begin{array}{lccc}\text { Urban } & 1 & 1 & 1 \\ \text { Rural } & 1.23 & 1.27 & 1.11\end{array}$

Education

$\begin{array}{lccc}\text { Enrolled } & 0.22 & 0.35 & 1.52 \\ \text { Low } & 1 & 1 & 1 \\ \text { Middle } & 0.60 & 1.02 & 1.59 \\ \text { High } & 0.54 & 1.29 & 2.05\end{array}$

Notes:

* Childless and not pregnant

** Childless and pregnant

${ }^{a}$ Standardized for current age (= process time in columns 1 and 2), calendar period, and number of siblings. (Effect differentials in the latter factor are ignorable for each entry risk.)

${ }^{\mathrm{b}}$ Correspondingly standardized for union duration (= process time in column 3), current age, calendar period, and number of siblings. Note the different role of current age (now a time-varying covariate) in this column. For age effects, see Figure 5.

${ }^{\mathrm{c}}$ Model with interaction between ethnicity and indicator of whether lived with parents at age 15 .

d The factors "ethnicity" and "whether lived with both parents at age 15" appear in interaction, as follows: With parents? $\quad$ Romanian Hungarian Roma Other

$\begin{array}{lcccc}\text { Yes } & 1 & 0.57 & 1.80 & 0.33 \\ \text { No } & 1.73 & 0.51 & 4.98 & 0.00\end{array}$


In our model for entry into a non-marital union, the ethnicity covariate (Factor $E$, say) turns out to appear in a strong interaction with whether the respondent lived with both parents at age 15 (Factor $P$ ). ${ }^{5}$ We show the interaction in Footnote $d$ of Table 1 and see that Romanians and particularly Roma have strongly elevated entry risks for cohabitation if they did not live with their parents at age 15. Not living with the parents at that age may be a sign of early entry into adulthood, which perhaps is a particularly important determinant (or in fact a consequence) of union entry for the Roma.

Women who grew up in a rural district have increased rates of entry into either type of union. Finally, as is common in most populations, our respondents have a reduced tendency to enter a union of either type as long as they are enrolled in education, and once they have finished studying, their rates of entry into marriage tend to increase with educational attainment while their entry rates for non-marital unions decrease.

\section{$\underline{\text { 5. Conversion of a non-marital to a marital union }}$}

In many populations, a consensual union is seen as a temporary arrangement on the way to marriage. To the extent that this is the case in the Romanian population, we would expect non-marital unions to be converted rather quickly into marriages. When behavior is represented by means of intensities, this would show up as high rates of union conversion at short union durations, which is also what we find in plots like Figure 3, which shows two versions of the outcome of a model specification of type $U C+B$. In Figure 3a, the interaction between union duration (Factor $U$ ) and calendar period (Factor $C$ ) is shown with duration along the $x$-axis and with one curve for each period. Figure $3 \mathrm{~b}$ is a different take on the same interaction, in that it shows how the conversion risk at each duration (measured in groups of months of duration) develops over calendar time. In both representations we see that unions are converted (from non-marital to marital status) most readily at early durations, but that this tendency is dampened over time and essentially disappears as we get into the first years of the $21^{\text {st }}$ century. These patterns show up more clearly (but also with less detail) in Figure 4, which contains a "pure" period effect in Figure 4a (as an average over union durations) and a similarly "pure" duration effect in Figure $4 \mathrm{~b}$ (as an average over calendar time). ${ }^{6}$ Figure 4 a shows that conversion risks have declined in steps over our entire period of observation.

\section{$<$ Figures 3a, 3b, 4a, and $4 b$ in about here $>$}

In this part of the analysis, the age factor $(A)$ appears as a time-varying covariate intended to catch the effect of age attained on the conversion risk. ${ }^{7}$ Figure 5 shows that this effect declines with increasing age, and is about two-thirds at age

\footnotetext{
${ }^{5}$ In our model for entry into marriage, adding the same interaction causes divergence of the iteration process that we use to find the maximum likelihood estimates.

${ }^{6}$ For model aficionados, Figure $4 \mathrm{a}$ is a plot of the estimated $c_{k}$ parameters and Figure $4 \mathrm{~b}$ a plot of the estimated $u_{i}$ parameters of an intensity specification of type $U+A+B+C$, which means that the analysis is standardized with respect to the other control variables collected in Factor $B$. The estimated $b_{j}$ parameters appear in the last column of Table 1 and the estimated age parameters $a_{h}$ have been plotted in Figure 5.

${ }^{7}$ Remember that process time is union duration (Factor $U$ ).
} 
30-34 of its impact at ages in the teens. (The last point in Figure 5 has an ordinate of 0.68 , relative to 1 at ages $15-19$.)

\section{$<$ Figure 5 in about here $>$}

The structure in the rates of conversion of non-marital to marital unions appears as relative risks in the final column of Table 1. Several features strike the eye:

1. A pregnancy will also raise the conversion rate, but "only" by about half and not nearly by as much as the first-entry rates increased, namely by a factor around 8 for each mode of entry. It is as if the interest that the prospective parents have in the circumstances of the birth are largely taken care of when the union has been established. There may also be an element of selectivity in this behavior, in that a couple who have entered a consensual union may be less interested in marriage even when the woman becomes pregnant.

2. The Roma have a particularly low conversion risk. It is as if conversion of an existing union into a formal marriage is less important to the Roma than to other members of the Romanian society, perhaps because many of our Roma respondents regard themselves as married even when a marriage has not been registered by the authorities, but this is not caught in the data collection. ${ }^{8}$

3. Enrolled respondents have particularly high rates of conversion, something that surprises us and calls for further reflection. The method we have used must include enrolment in unorthodox forms of education, such as in after-work highschools, tertiary education by distance learning, and so on (Mureşan 2007b). Young people who choose such forms of education probably regard marriage as a needless complication initially and start their unions as non-marital, but subsequently seek marriage as a socially better approved form of partnership. For respondents who have completed their education, conversion rates increase strongly with educational attainment.

\section{Conclusions and reflections}

Our study suggests that certain features of the narrative of the Second Demographic Transition can be discerned in Romania over the last forty years or so. In particular, the rate of marriage formation dropped precipitously after the fall of state socialism in 1990. The rate of entry into cohabitation has been much lower over our entire period of observation, but it is important that it has not been negligible. It has also increased gradually since the early 1960s, though the change in the political system made no major impact on it. Despite its low level this incidence was subject to visible differentials between population groups. In particular, respondents recorded as Roma had a higher incidence of cohabitation than others while those who called themselves ethnic Hungarians had unusually low entry rates (of both kinds) for reasons that we refrain to speculate over. A pregnancy boosted entry rates considerably, perhaps in reflection of a long-standing pattern of avoidance of single (actually unpartnered) motherhood.

\footnotetext{
${ }^{8}$ A possible explanation may be that in the Roma population a first union is the outcome of a negotiation between the families of the bride and the groom. The union may then be a recorded marriage (with a marriage certificate from the state) or a non-marital union regarded as a marriage by the Roma natives if it was approved and celebrated by their community. Once the union has been established there may be less interest in transforming it into a recorded marriage.
} 


\section{Acknowledgement}

We are grateful for insightful comments from Gerda Neyer.

\section{References}

Hoem, Jan M. and Michaela Kreyenfeld (2006). Anticipatory analysis and its alternatives in life-course research. Part 1: The role of education in the study of first childbearing. Demographic Research 15 (16), 461-484.

Hoem, Jan M., Dora Kostova, Aiva Jasilioniene, and Mureşan, Cornelia (2007). Traces of the Second Demographic Transition in four selected countries in Central and Eastern Europe: Union formation as a demographic manifestation. MPIDR Working Paper WP-2007-026.

Hoem, Jan M. and Dora Kostova (2008). Early traces of the Second Demographic Transition in Bulgaria: a joint analysis of marital and non-marital union formation, 1960-2004. Population Studies 62 (3), 1-13.

Koytcheva, Elena (2006). Social-demographic differences of fertility and union formation in Bulgaria before and after the start of the societal transition. MPIDR doctoral dissertation, University of Rostock.

Kulik, Margarete C. (2005). The emergence of cohabitation and its later stability: the case of Hungarian women. MPIRD working paper, http://www.demogr.mpg.de/papers/working/wp-2005-031.pdf

Lesthaeghe, Ron and Dirk J. van de Kaa. (1986). Twee demografische transities? In.: Dirk J. van de Kaa and Ron Lesthaeghe (eds.), Bevolking: groei en krimp. Van Loghum Slaterus, Deventer, pp. 9-24.

Manting, Dorien (1996). The changing meaning of cohabitation and marriage. European Sociological Review 12(1), 53-65.

Michael, Robert T. and Nancy B. Tuma (1985). Entry into marriage and parenthood by young men and women: the influence of family background. Demography 22(4), 515-544.

Mureşan, Cornelia, Paul-Teodor Hărăgus, Mihaela Hărăgus, and Christin Schröder (2008). Romania: Childbearing metamorphosis within a changing context. Demographic Research 19 (23), 855-906.

Mureşan, Cornelia (2007a). Family dynamics in pre- and post-transition Romania: a life-table description. MPIDR working paper, http://www.demogr.mpg.de/papers/working/wp-2007-018.pdf.

Mureşan, Cornelia (2007b). Educational attainment and second births in Romania. MPIDR working paper, http://www.demogr.mpg.de/papers/working/wp-2007028.pdf

Santow, Gigi and Michael Bracher (1994). Change and continuity in the formation of first marital unions in Australia. Population Studies 48, 475-496.

Sobotka, Tomáš (2008). Overview Chapter 6: The diverse faces of the Second Demographic Transition in Europe. Demographic Research 19 (8), 171-224.

Sobotka, Tomáš, Kryštof Zeman, and Vladimira Kantarová (2003).Demographic shifts in the Czech Republic after 1989: a Second Demographic Transition view. European Journal of Population 19, 249-277. 
Figure 1. Trends in union-entry risks, model $A+B+C D$, Romania

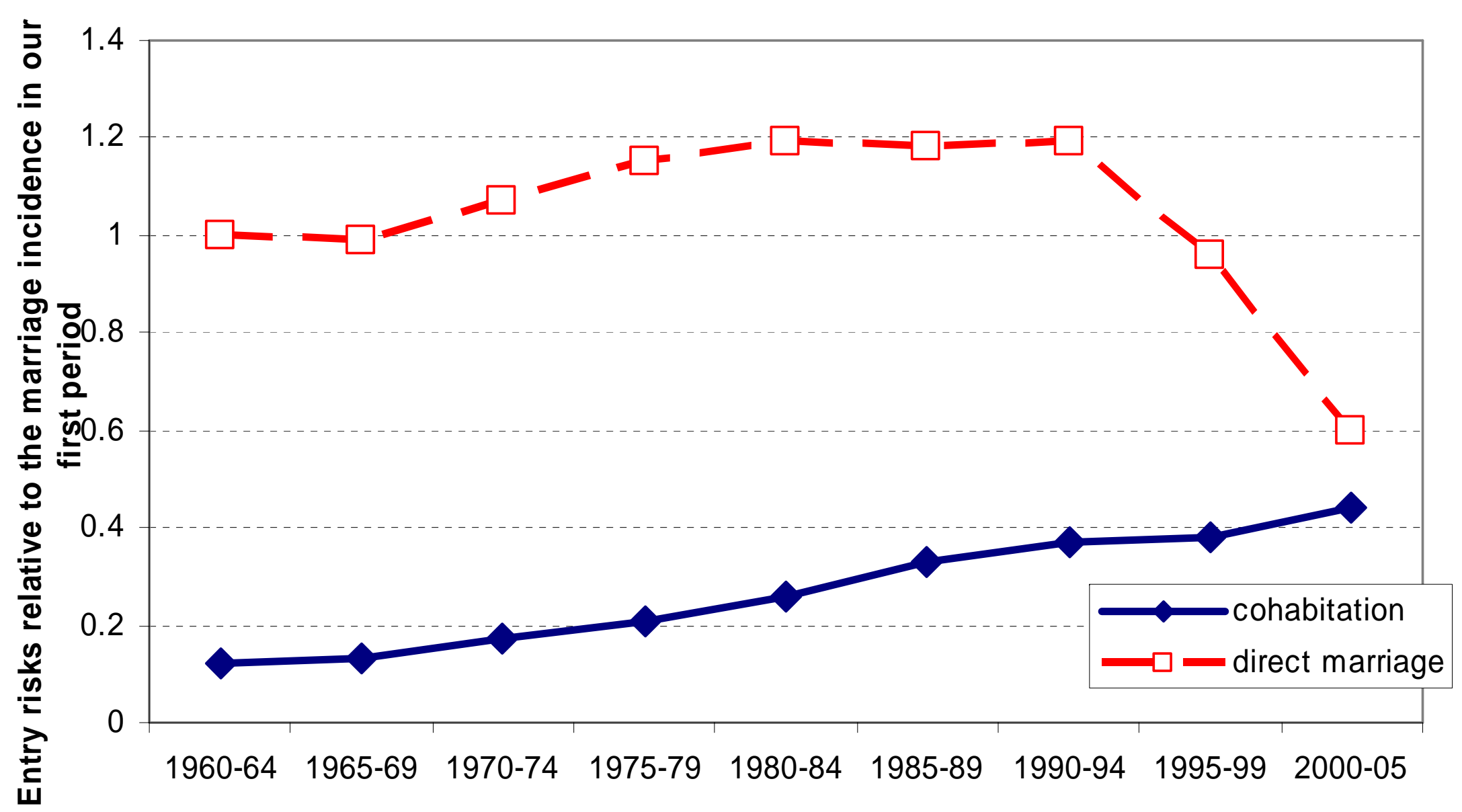


Figure 2. Age profiles, single decrements. Romania, $A+B+P E+C$

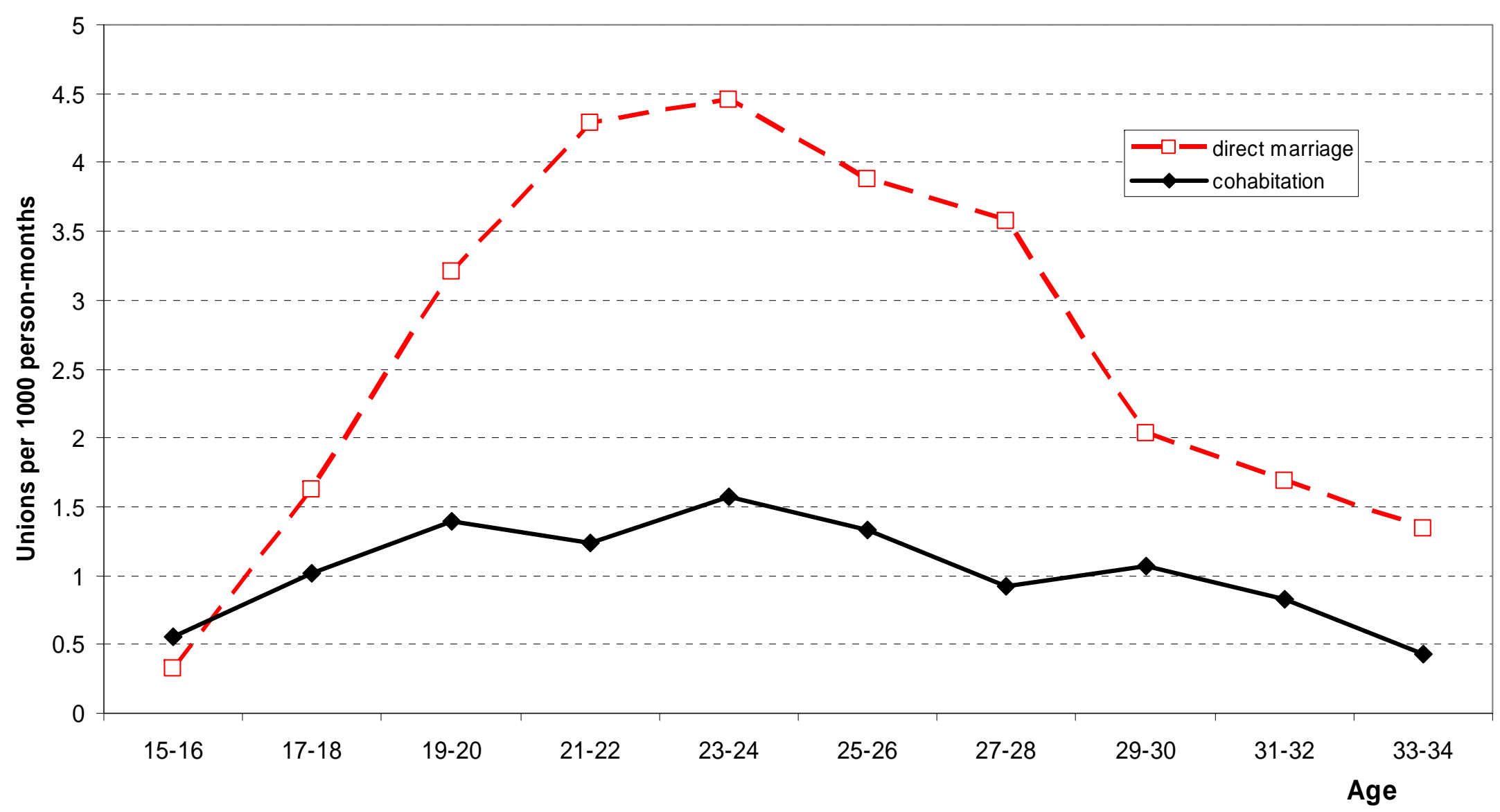


Figure 3a. Conversion risk by duration of union, for selected periods.

Romania 1960-2005

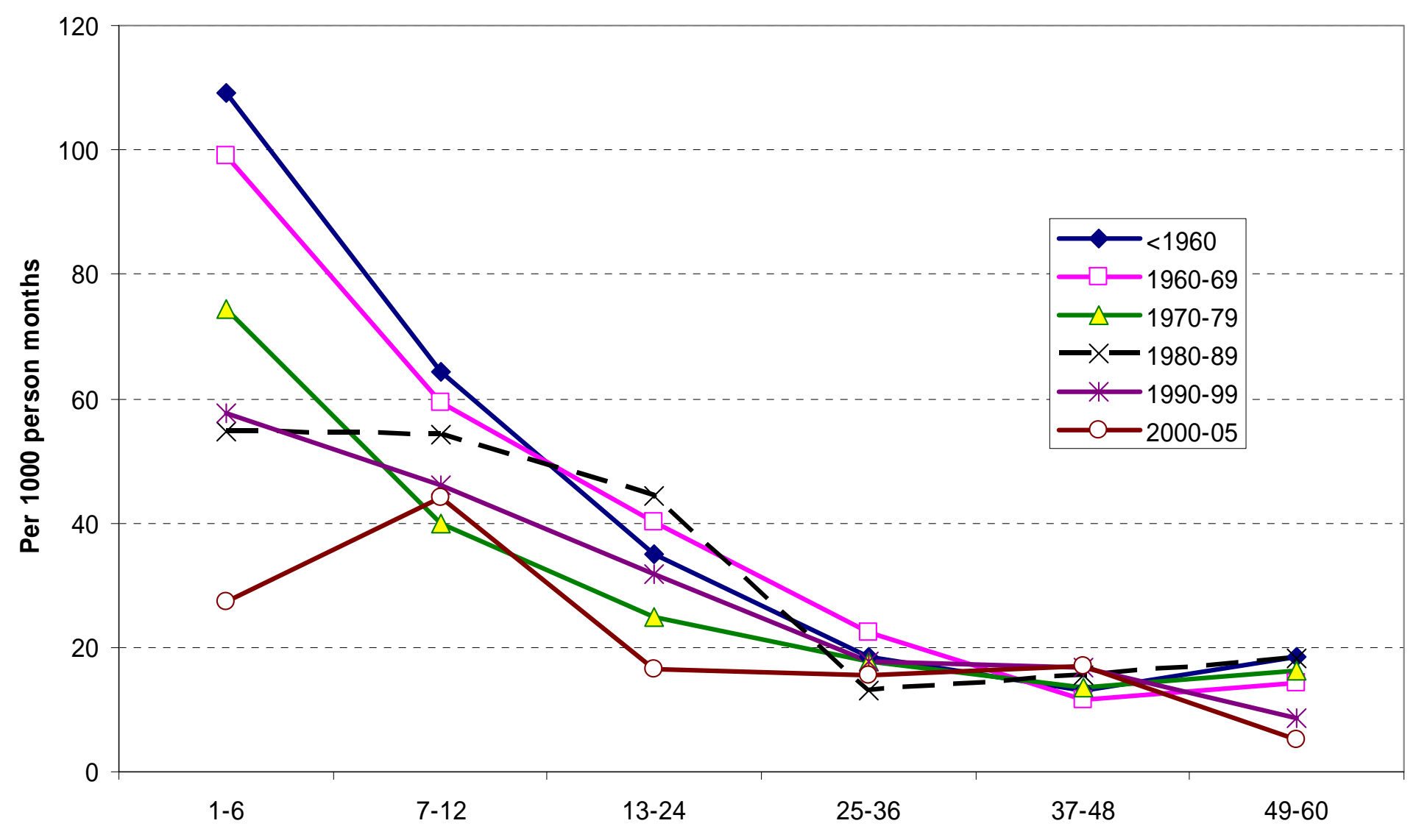


Figure 3b. Risk of union conversion, by period, for selected months of duration. Romania 1960-2005

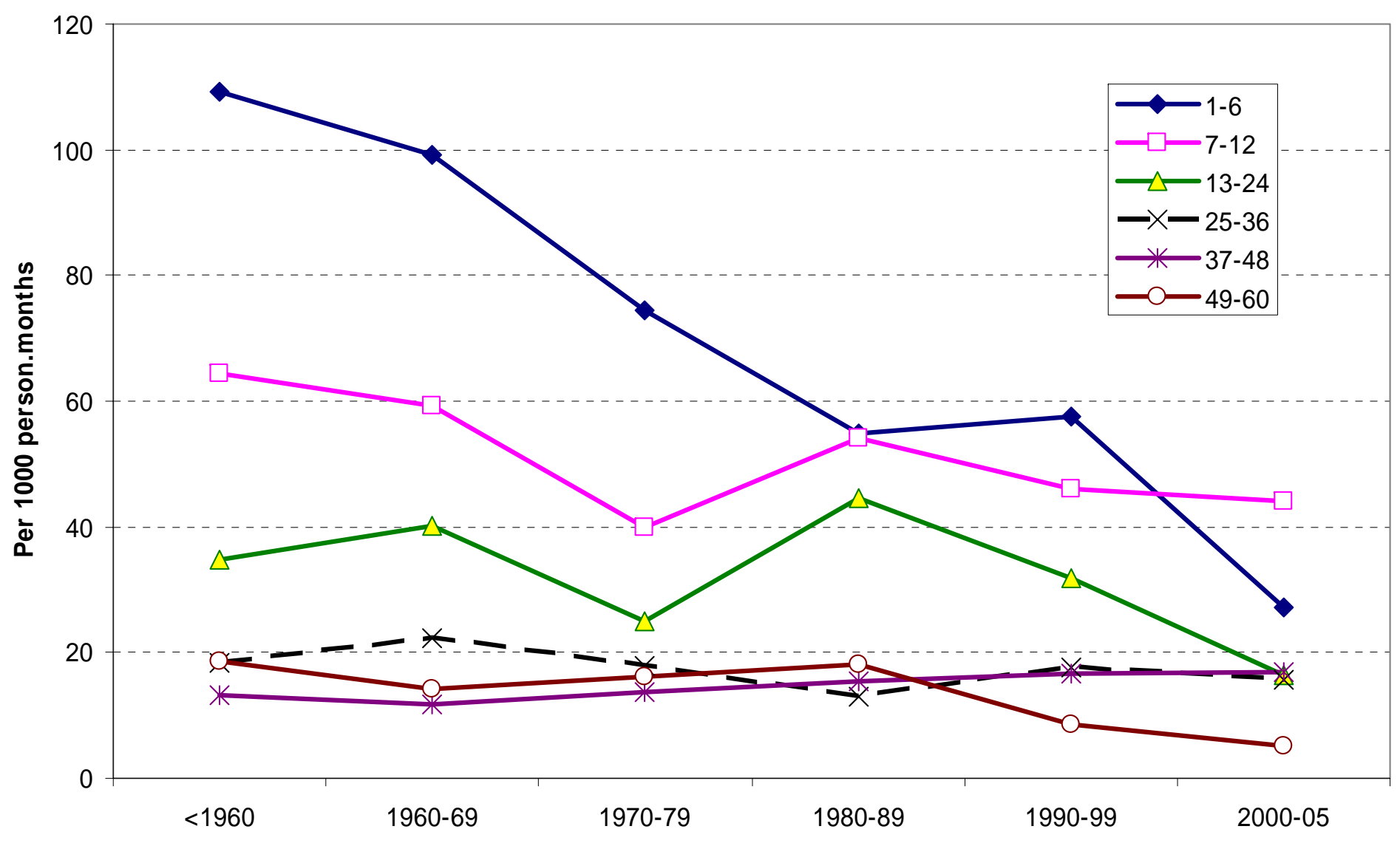


Figure 4a. Conversion trend. Romania 1960-2005

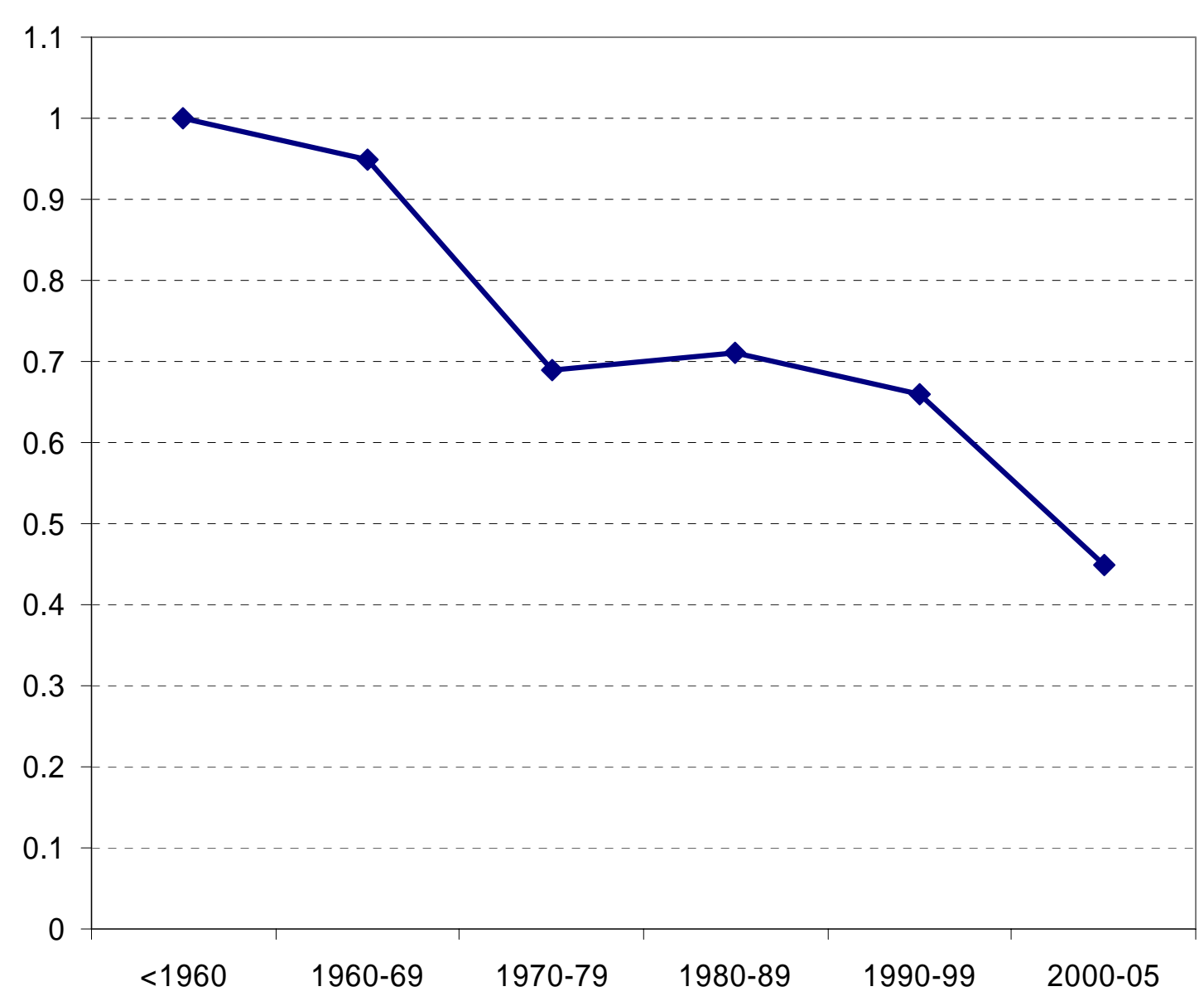


Figure $4 \mathrm{~b}$. Conversion risk by month s of cohabitation.

Romania 1960-2005

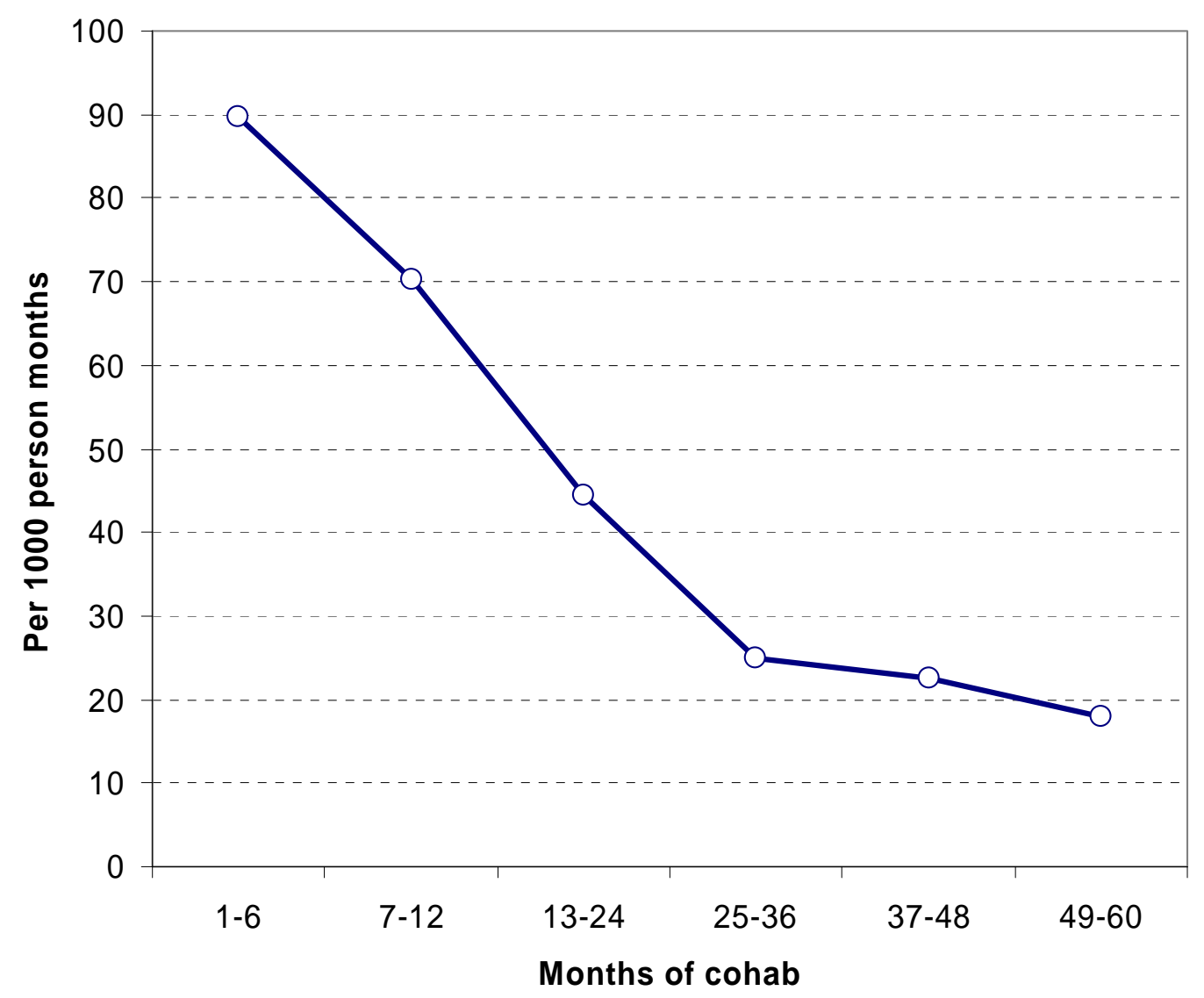


Figure 5. Age profile in conversion risk. Romania 1960-2005

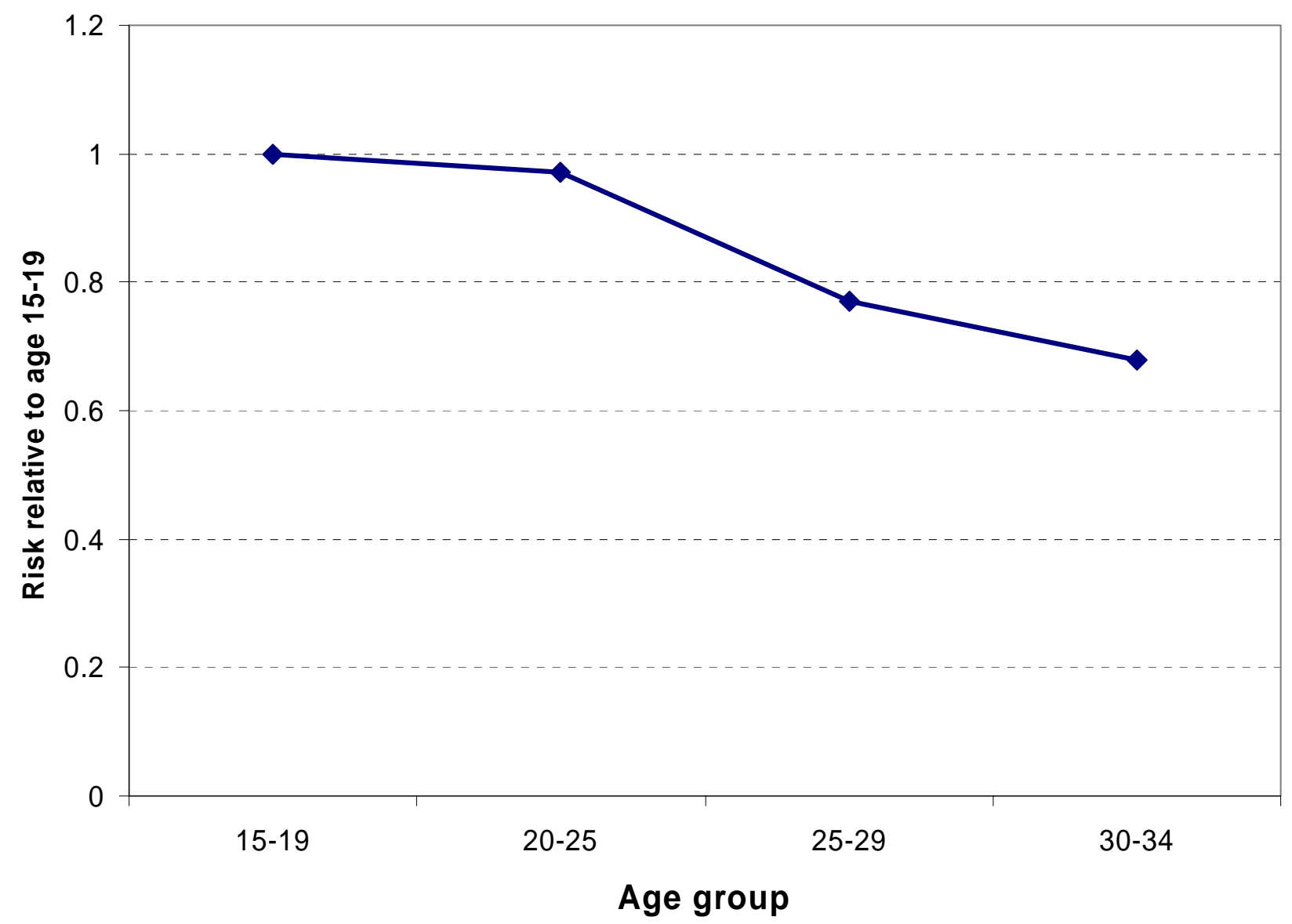

